\title{
Benefits of Optimisation and Model Predictive Control on a Fully Autogenous Mill with Variable Speed
}

\author{
C.W. Steyn, C. Sandrock* \\ Department of Chemical Engineering, University of Pretoria, c/o Roper and Lynwood \\ Road, Pretoria, South Africa \\ * corresponding author: carl.sandrock@up.ac.za
}

\begin{abstract}
Autogenous (AG) milling is utilised around the world for particle size reduction. The system exhibits highly non-linear behaviour in addition to being subject to unmeasured variability associated with most ore bodies. Anglo American Platinum aimed at improving online optimisation of the circuit by implementing industrial model predictive control (MPC) to reduce system variability and continuously drive towards the optimal operating point within system constraints.

The industrial dynamic matrix controller commissioned on the AG mill with a variable speed drive resulted in a $66 \%$ reduction in power and a $40 \%$ reduction in load standard deviation. These are the main controlled variables of the mill. The controller also improved the objective function, effective power utilisation, by $11 \%$. This reduction in operated variable variability enabled a test campaign where the mill was controlled at various operating regions in order to establish the conditions conducive to the finest product size at a given mill feed rate.

Moving the mill operating region from the benchmarked plant to the optimal grind environment and stabilising the mill at this point with the model predictive controller provided an estimated potential recovery increase of $0.32 \%$ (absolute) due to better liberation.
\end{abstract}

Keywords: autogenous, milling, optimisation, response surface analysis, model based control, benefit analysis, variable speed 
Table 1: List of Variables

\begin{tabular}{ll}
\hline Symbol & Description \\
\hline $\mathrm{CV}$ & Controlled variable \\
$\mathrm{MV}$ & Manipulated variable \\
$\mathrm{J}$ & Objective function \\
$\mathbf{f}$ & Open loop response vector of the system \\
$S S C$ ost & Steady state cost for MV $i$ \\
$\mathbf{G}$ & The multi-variable free response matrix of the system \\
$\mathbf{y}$ & System outputs $(\mathrm{CV}$ ) \\
$\mathbf{u}$ & System inputs (MVs) \\
$\eta_{\text {power }}$ & Effective power utilisation of the milling circuit in \\
& kWh/t(passing $75 \mu \mathrm{m})$ produced \\
$S$ & Mill speed in \% critical speed \\
$W_{\text {rat }}$ & Mill inlet water ratio \\
$F$ & Mill ore feed in tph \\
$G$ & Product grind in \% passing $75 \mu \mathrm{m}$ \\
$P R$ & Potential Recovery \\
$P(i)$ & Profit function in terms of variable $i$ \\
$C(i)$ & Cost function in terms of variable $i$ \\
$P N P$ & Potential net profit \\
$P F$ & Performance function \\
\hline
\end{tabular}

\section{Introduction}

A large portion of the total operating cost in the mineral beneficiation process is associated with comminution circuits. The highest costs in these operations are normally grinding media and energy. Since the global economic downturn at the end of 2008, the control of these cost elements, together with optimised performance especially on the milling component of these circuits, has become increasingly important.

Anglo American Platinum employs numerous fully autogenous (AG) primary mills. All are under Neuro-Fuzzy control, applied in a manner suitably robust to perform in the non-linear, highly unmeasured environment of primary milling (Steyn et al., 2010). These mills have recently been fitted with model predictive controllers that enable real-time optimisation and minimise 
a power utilisation objective function $\left(\mathrm{kWh} / \mathrm{t}_{-75 \mu m}\right)$. The algorithm was originally piloted on one of Anglo American Platinum's ROM mills, Mototolo JV. The success of the controller was immediately evident, demonstrating a reduction in variability of between $15 \%$ and $20 \%$ on the primary milling parameters (see figure 1) and also improving energy efficiency. A reduction in controller input variance with a clear bias towards the local optimum in the top left corner of the feasible region is indicated in figure 1.
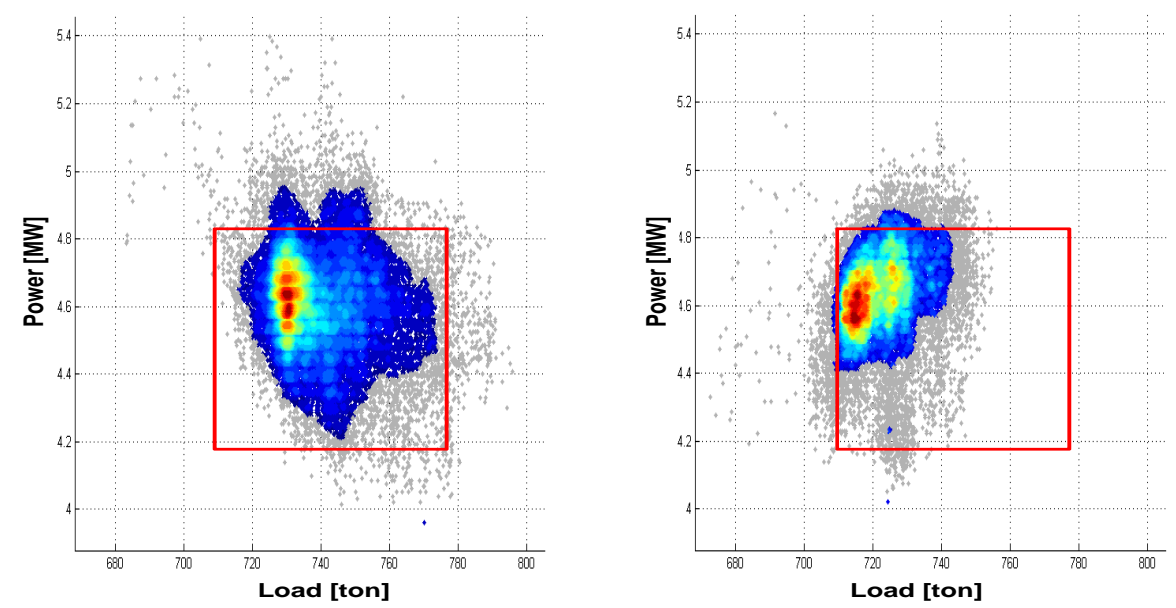

Figure 1: A 2D density plot of the power and load for Mototolo (JV) ROM primary mill on data a)two weeks prior and b) two weeks post MPC implementation.

The next step in the milling optimisation initiative was to implement a similar solution on its AG mills with the following objectives:

1. Obtain similar variability reduction in the system's main controlled variables, power and load

2. Find the optimal operating using grindcurves (Powell and Mainza, 2006; van der Westhuizen and Powell, 2006) and exploit this in the MPC algorithm to operate the mill in a way that maximises financial benefit

3. Quantify the real benefits of reducing the variability in the mill and stabilising the circuit at the optimum operating conditions 
The primary AG mill at Rustenburg Platinum Mines Amandelbult UG2 No2 (RPMA2) plant was selected for this application due to the additional potential of its variable speed facility. To achieve the objectives listed above, the following goals were established:

Benchmark the system based on the key performance indicators that have been established for comminution circuits.

Model the relationship between the identified variables in a dynamic empirical model suitable for use in an online controller.

Optimise the operation of the mill by utilising the improved circuit stability in a trial to determine the optimal operating region.

Analyse the benefits that the advanced controller introduces to the system.

\section{Circuit Benchmark}

\subsection{Process Description}

Rustenburg Platinum Mines Amandelbult UG2 No.2 (RPMA2) is one of Anglo American Platinum's mineral ore processing plants situated in the North West province of South Africa. Ore from the mine undergoes one stage of top size reduction in a primary jaw-crusher before it is classified by a $100 \mathrm{~mm}$ grizzly screen and conveyed to the fine and coarse ore silos. The fine and coarse ore is treated by a $6.1 \mathrm{~m} \phi \times 8.5 \mathrm{~m}$ fully autogenous primary mill (see figure 2). Autogenous mills are defined by the ore being the only source of grinding media and the absence of a secondary media such as steel. The circuit is operated in a closed loop with a horizontal vibrating screen fitted with $630 \mu \mathrm{m}$ polyurethane classification panels. The oversize from the screen is recycled to the feed of the mill while the undersize particles are gravity fed to an agitated $200 \mathrm{~m}^{3}$ flotation feed surge vessel (rougher feed tank).

\subsection{Control Infrastructure}

Anglo American Platinum follows a two-tiered approach when controlling its primary mills. The top tier consists of an in-house developed supervisory advanced control system that is based on fuzzy-logic rules and cascades to the bottom tier base-layer control schema (Steyn et al., 2010). The base-layer 
control of the circuit runs on the PLC which accounts for the PID control algorithms, interlocks and sequences. The mill is controlled by providing three manipulated variables (MVs) with setpoints from either the humanmachine interface (HMI) or the advanced control layer. These MVs are (use figure 2 as reference):

Total ore feed-rate Controlled by a PID controller that cascades down to a coarse ore ratio controller. The total ore process variable PV is obtained from a weightometer situated on the combined ore (fine + coarse) feed belt.

Coarse ore ratio This is the ratio of coarse ore mass flow to total ore mass flow (excluding the recycled ore). The ratio controller cascades to two ore feed rate PID controllers, which both receive their PVs from weightometers situated on the coarse and fine ore feed conveyor belts and actuate the respective ore feeders.

Inlet water ratio The PV of this controller is the calculated ratio of inlet water flow to total ore fed to the mill. The SP is assigned to a ratio controller that cascades down to a flow PID controller which actuates the inlet water control valve.

The advanced milling controller at RPMA2 utilises a $3 \times 3$ Quasi-Fuzzy Rules-Based controller that uses the same SP as the base layer to control the power, load and screen current of the circuit. An MPC with real-time optimisation was added to the advanced layer. The MPC is used during normal operation, but control is switched to the fuzzy system during abnormal situations. The selection between the two algorithms is governed by the supervisory controller that detects normal or abnormal conditions based on process state rules.

\subsection{Controller Design and Implementation}

In this instance, Anglo American Platinum has used AspenTech DMCplus ${ }^{\text {TM }}$ as the platform to develop its model predictive control infrastructure.

\subsubsection{Control Law for DMCplus ${ }^{T M}$}

The model predictive control solution is computationally intensive and in some cases it is difficult to ensure feasibility when solving the quadratic objective function given in equation 1 . 


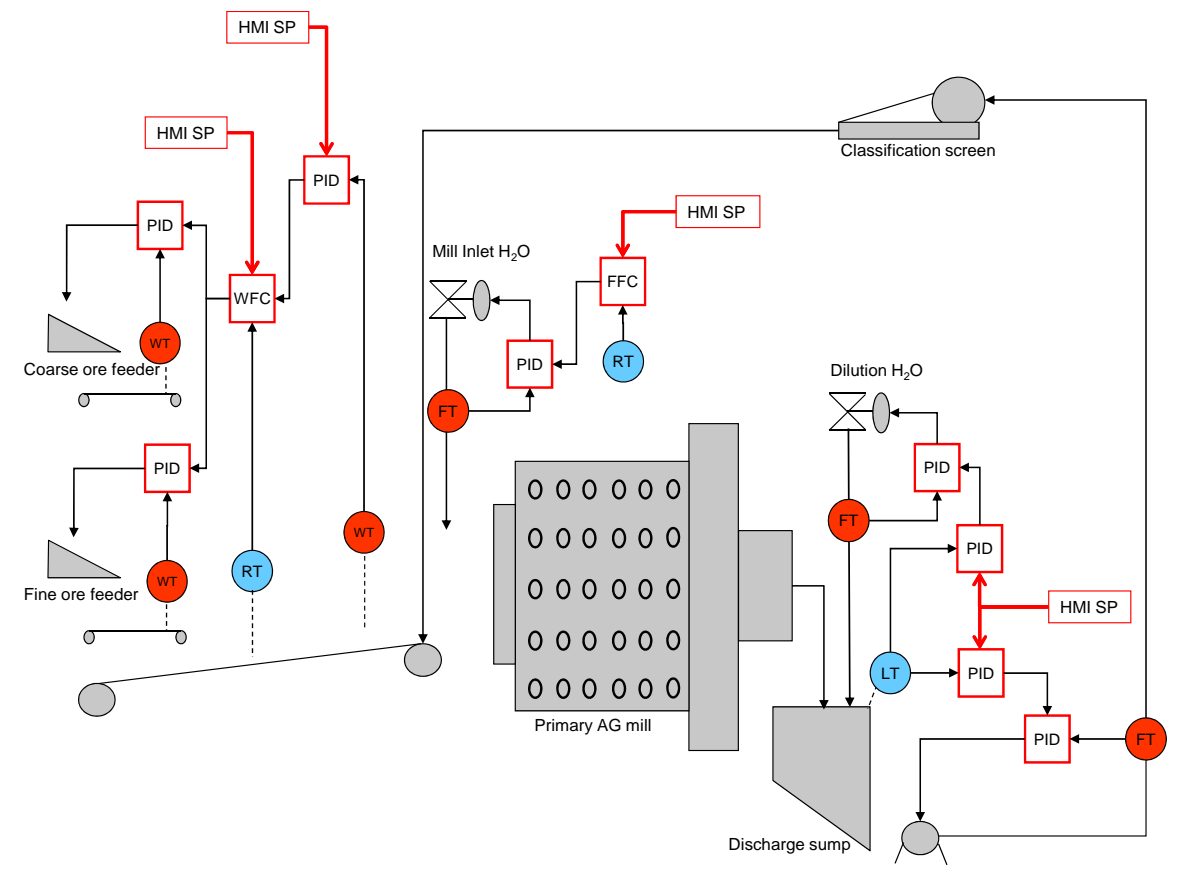

Figure 2: Anglo American Platinum's primary milling base-later control infrastructure at RPMA2 


$$
J\left(N_{1}, N_{2}, N_{u}\right)=\sum_{j=N_{1}}^{N_{2}} \delta(j)[\hat{y}(t+j \mid t)-\omega(t+j)]^{2}+\sum_{j=1}^{N_{u}} \lambda(j)[\Delta u(t+j-1)]^{2}
$$

In an attempt to industrialise the algorithm, AspenTech developed a staged procedure where feasibility is ensured upfront (possibly by relaxing constraints). This enables an analytic solution of the MV trajectory. This four staged procedure is explained as follows with each cycle abiding to the routine (AspenTech, 2000):

1. Open Loop Prediction The open-loop prediction or free response of the system can be extended as the sum of four effects; $\mathbf{f}_{u}$ the response of the system due to past control movement, $\mathbf{D d}+\mathbf{f}_{d}$ the response to known disturbances and $\mathbf{f}_{n}$ unmeasured system disturbances or model error.

$$
\mathbf{f}=\mathbf{f}_{u}+\mathbf{D d}+\mathbf{f}_{d}+\mathbf{f}_{n}
$$

2. Obtaining a Feasible Solution The next step in the DMCplus ${ }^{\mathrm{TM}}$ control law is to determine whether a feasible solution is possible for any combination of inputs. A feasible solution is possible when the allowed MV movement within the MV constraints can bring all the CVs within limits (figure 3). If no solution is available, the algorithm will relax its CV limits in accordance to a rank of importance.

As soon as a solution is available, the algorithm proceeds to the next step with an updated set of CV limits required for a feasible solution.

3. Steady-State Optimisation The aim of optimisation is to minimise the objective function for a given system within the allowable process constraints (Snyman, 2005). The mathematical form of this constrained problem is given as follows:

$$
\min f(x), \quad x=\left[x_{1}, x_{2}, \ldots, x_{n}\right]^{T} \in \mathbb{R}
$$

Subject to constraints usually of the form:

$$
\begin{aligned}
g_{j}(x) & \leq 0, & j & =1,2, \ldots, m \\
h_{j}(x) & =0, & j & =1,2, \ldots, r
\end{aligned}
$$

The AspenTech framework (DMCplus ${ }^{\mathrm{TM}}$ ) allows for the usage of either linear or quadratic programming (AspenTech DMCplus ${ }^{\text {TM }}$ course notes): 


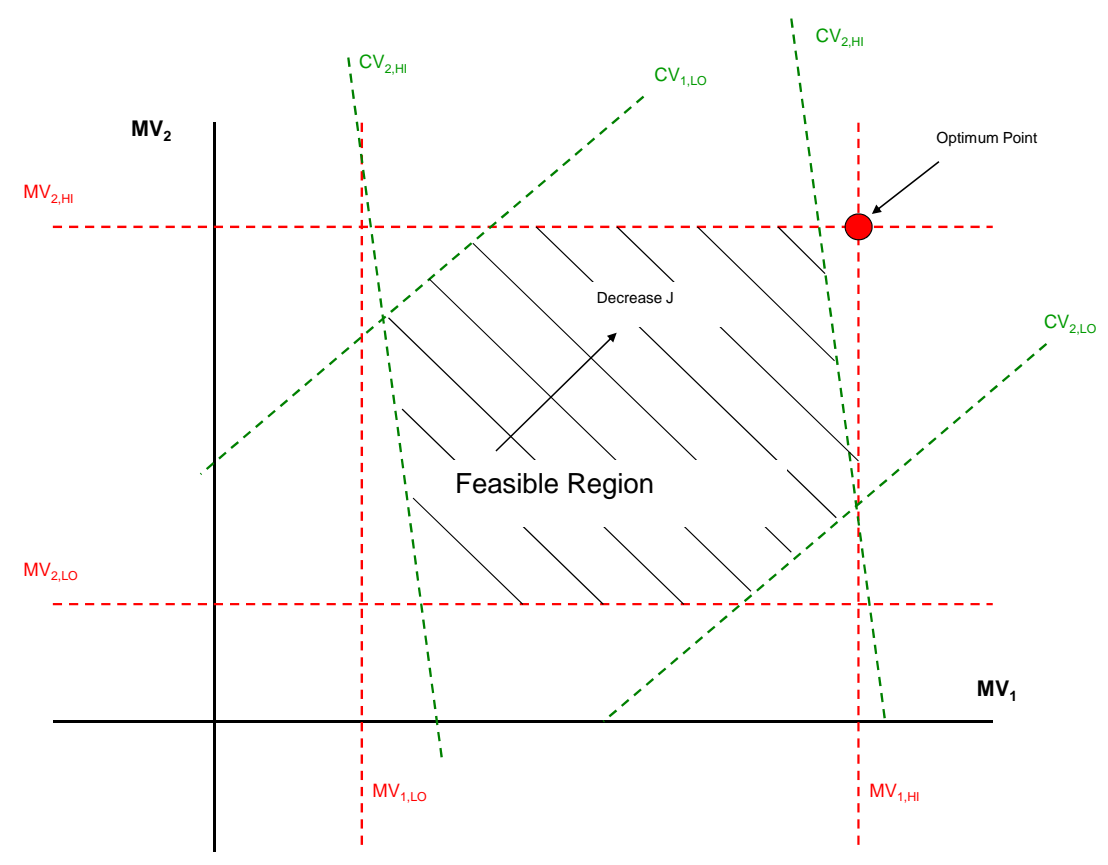

Figure 3: Graphical representation of the feasible region defined by MV and CV constraints 
(a) Linear Programming A special case of general optimisation arises when both the objective function and the constraints are linear functions (Snyman, 2005). Such an instance is called linear programming, stated in the following form:

$$
\min _{x} f(x)=\mathbf{c}^{\mathbf{T}} \mathbf{x}
$$

such that

$$
\mathrm{Ax} \leq \mathrm{b}
$$

Within DMCplus ${ }^{\mathrm{TM}}$ the vector $\mathbf{c}$ in equation 4 is an $n$-vector containing the steady-state cost parameter SSCost allocated to each manipulated variable. The $S S C$ ost vector represents the direction of minimising the linear programming objective function. $\Delta u_{s s}$ represents the steady state MV step conducive to the lowest J:

$$
\min J=\sum_{i=1} n\left(S S \text { Cost }_{i} \times \Delta u_{s s}\right)
$$

(b) Quadratic Programming The objective function is defined as a positive-definite quadratic function subject to these linear constraints (Snyman, 2005). The minimisation function in DMCplus ${ }^{\mathrm{TM}}$ is given by:

$$
\min J=\left(\sum_{i=1} n\left(\text { SSCost }_{i} \times \Delta u_{s s}\right)-M\right)^{2}
$$

Where the maximum profit, $M$, is defined as the point on a plane only subject to MV constraints (represented as "Optimum Point" in figure 3)

4. Future $M V$ movement The next step in the DMC control law is to calculate the future input movement in order to get the outputs to the steady-state end values.

(a) Minimise CV Error

$\mathrm{CV}$ error $e$ in this instance is defined as the difference between the open loop response and the steady state value (or SP). MV movement to achieve minimum $\mathrm{CV}$ error is given as:

$$
\Delta u=\left[G^{T} G\right]^{-1} G^{T} e
$$


(b) Minimise $M V$ movement

Minimising CV error in the most aggressive manner might provide the best control solution. Model error, circuit constraints etc. can however, induce cycling and other unwanted control effects if aggressive MV movement is allowed. An MV movement suppression parameter $K$ is added to equation 7 where:

$$
K \cdot \Delta u=0
$$

The components in equation 7 change as a result of MV minimisation (equation 8) to:

$$
\mathbf{G}^{\prime}=\left[\begin{array}{c}
G \\
K I
\end{array}\right]
$$

(c) CV Importance

To distinguish between the importance of various CVs, a weight $W_{i}$ is assigned to the error of each CV.

$$
\Delta u=\left[G^{\prime T} G^{\prime}\right]^{-1} G^{\prime T} e W
$$

\subsubsection{Modelling}

DMCplus ${ }^{\mathrm{TM}}$ conducts its process modelling by means of a step-test campaign where all the independent parameters are moved in order to produce responses from the dependent variables. Furthermore, DMCplus ${ }^{\mathrm{TM}}$ utilises finite-impulse-response as well as state-space modelling (Camacho and Bordons, 2007), as techniques to determine the matrix of linear models describing the milling circuit relationships.

The following characteristics are observed from the response matrix obtained during September 2010:

\section{General.}

1. The model horizon (or prediction horizon) of the controller that produced the most reliable models was 60 minutes.

2. One of the most significant observations is that the mill load behaviour is described as an integrator over the allocated model horizon.

3. The inlet water ratio to mill power model presented a positive gain for the operating region of the mill. This indicates, according to Morell and Kojovic (1996), that the flowrate through the mill is low enough for the interstices within the charge not to be completely occupied and that no slurry pool has formed. 
4. Speed increases produced a positive, higher order, underdamped response from power which concurs with the findings of van der Westhuizen and Powell (2006).

Model Gain. If the system is scaled according to input range and output error (Skogestad and Postlethwaite, 2005), the ore feed yields the largest power gain with inlet water the second highest. Mill speed yields the largest gain on mill load for both scaled and unscaled models with inlet water ratio in second. It is noticeable that the coarse ore ratio produced the lowest scaled gain for both power and load.
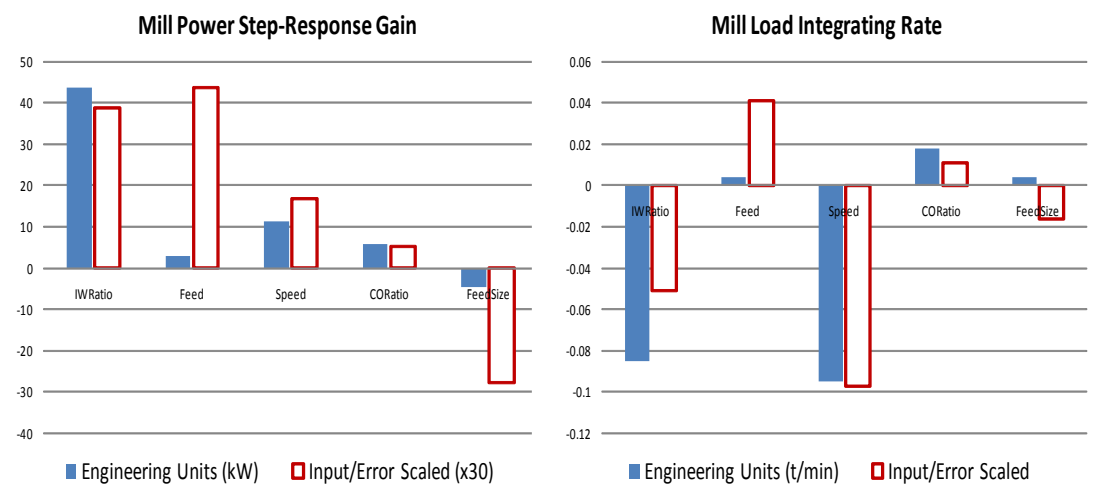

Figure 4: The step-response model gain and integrating rate for mill power and load respectively

\subsubsection{Objective Function}

The objective of this controller is to minimise the effective power usage $\eta_{\text {power }}$ of the milling circuit, in units $\mathrm{kWh} / \mathrm{t}_{-75 \mu m}$. The direction and magnitude of the SSCost vector in equation 5 are obtained by modelling the effective power usage of the mill to the speed and inlet water ratio.

In the absence of an online measurement, the 8 hour (shiftly) composite grind samples are used to calculate $\eta_{\text {power }}$. This calculation is used to model the objective function using the manipulated variables speed $S$, inlet-water ratio $W_{\text {rat }}$ and mill feed rate $F$. A linear fit was performed where, as per equation 5, the SSCost vector is defined by the model coefficients. 450 valid shiftly samples were obtained during the period 1 January 2010 to 1 October 
2010. The linear regression model achieved an $R^{2}=20 \%$ which is fairly low under normal circumstances. However, taking into account that composite average samples over an 8 hour period were used, this model was assumed to be good enough to serve as an indication for the optimisation directions. A pure-quadratic regression was also carried out in order to validate the directionality of the linear model. A root-mean-square-error (RMSE) equal to $1.7 \mathrm{kWh} / \mathrm{t}_{-75 \mu m}$ was achieved, which relative to $\eta_{\text {power }}$ equates to an acceptable $R M S E_{\text {rel }}$, equal to $7 \%$. Both the linear and pure-quadratic model resulted in positive coefficients for water and speed but negative for feed. The linear objective function obtained used for the DMCplus ${ }^{T M}$ controller's steady-state optimisation can thus be presented dynamically as:

$$
\Delta J=\Delta \eta_{\text {power }}=6.6+0.27 \Delta S+0.165 \Delta W_{\text {rat }}-0.022 \Delta F
$$

\section{Optimisation}

\subsection{Optimisation Strategy}

As explained, the mill feed maximisation is regarded as the primary objective and mill speed minimisation as secondary. In doing this, the mill inlet water will be moved and kept at its high limit, to allow maximum speed reduction. This is due to the fact that the inlet water ratio shares a gain and optimisation directionality with speed (considering load). The three degrees

of freedom available to the system are consumed by the feed high limit, the load high limit due to reducing speed and the inlet water ratio high limit. This optimisation strategy means that the mill will be fed at the target feed rate while operated at an optimum viscosity (Klimpel, 1983; Napier-Munn et al., 1999), optimum volumetric fill and lowest speed (van der Westhuizen and Powell, 2006). The last three factors ensure the highest possible grind for the given ore target.

\subsection{Optimisation Framework}

The objective of this framework is to verify the optimum operating region of the mill, defined for a certain throughput, at the load and inlet water ratio high limits. As the benefit of milling circuits is usually expressed in terms of liberation or particle size distribution of the product (Hulbert, 2002; SosaBlanco et al., 2000; Hodouin et al., 2001), the optimal operating region is defined as the limits conducive to the best grind. These limits were obtained by conducting two optimisation trials. 
First, the grind to load relationship was determined by operating the mill at three different load high limits. The grindcurves which resulted from the first trial suggest a second order polynomial grind/load model:

$$
\left.G(L)\right|_{W_{\text {rat }}=0.24}=-0.011 x^{2}+4.4 x-421.4
$$

The maximum grind is obtained at $\frac{\mathrm{d} y}{\mathrm{~d} x}=-0.022 x+4.4=0$ which equates to a mill load of $V_{\text {Grind,max }}=211.2$ ton mill load (see figure 5 ). The average power obtained at these operating regions also formed a parabola with maximum power of $2900 \mathrm{~kW}$ achieved to the left of $V_{\text {Grind,max }}$.

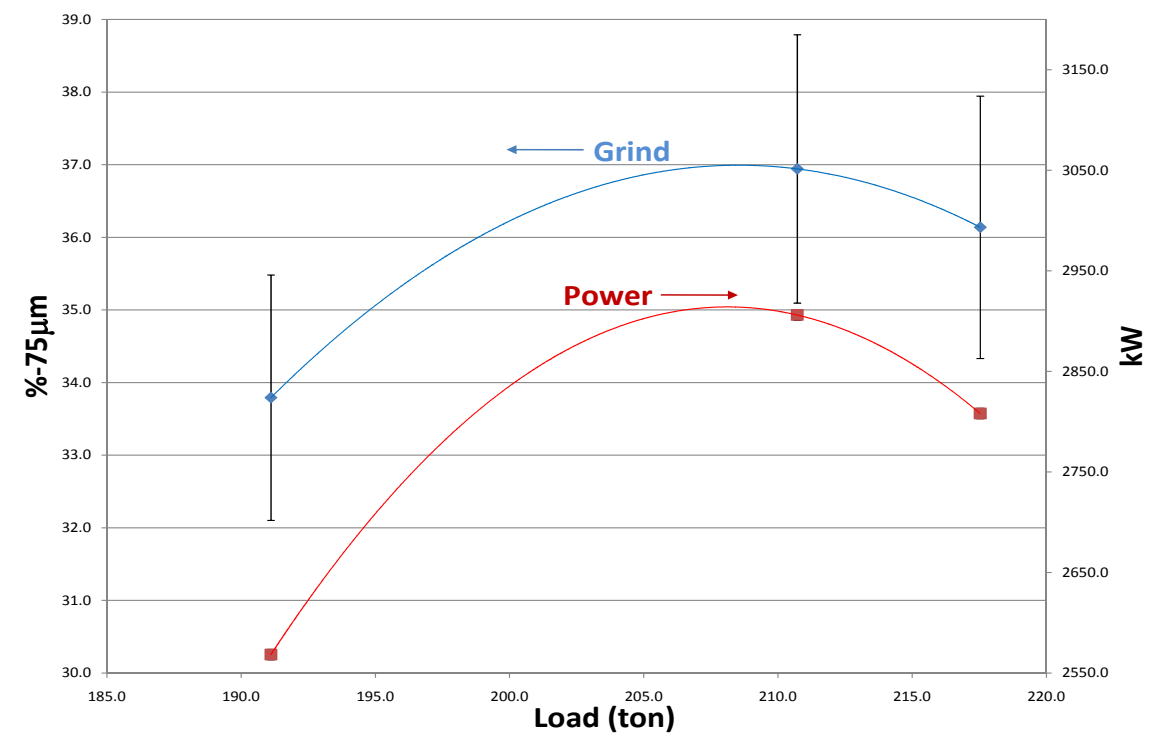

Figure 5: RPMA2 primary AG Mill grindcurves

Next the effect of inlet water on grind was determined. Note that this trial was aimed at expanding the response surface on the inlet water axis. The response surface of the load and inlet-water resulted in a model that obtained a root-mean-square-error value of $1.06 \%$ or $3 \%$ relative to the mean of the grind. The pure-quadratic relationship of load and inlet water ratio on grind is given as follows:

$$
G^{\prime}\left(L, W_{\text {rat }}\right)=-0.0076 \cdot L^{2}+3.2 \cdot L+266 \cdot W_{\text {rat }}-592.48 \cdot W_{\text {rat }}^{2}-336.6
$$


The point which maximised the grind based on equation 13 is obtained at $\frac{\partial G}{\partial L}=0$ and $\frac{\partial G}{\partial W_{\text {rat }}}=0$ for load and inlet water ratio, respectively. This amounts to a load of $L_{\text {opt }}=213$ ton and an inlet water ratio of $W_{\text {rat }}=0.224$. It is important to note that this is only an empirical model, applicable to the primary mill and UG2 ore body of RPMA2 at a nominal feed rate of $350 \mathrm{t} / \mathrm{h}$. Due to the seemingly high model error this optimum is not considered exact but rather an approximate optimal operating region of the mill.

\subsection{Performance Results}

As a preliminary indication of the MPC performance, the first month of operation (19 October to 22 November 2010) was compared to the baseline Fuzzy-logic Controller (FLC) performance during the period 1 August 2010 to 9 September 2010. Only good quality data at a sampling rate of 1 point per minute was used. This produced 16430 good data points during the MPC period and 17180 during the FLC period. Good data was defined as plant running data, determined by whether the mill was receiving a feed rate higher than 100 tph.

The following results were observed:

Mill Load and Power The mill load standard deviation was decreased from 6.8 ton to 2.3 ton, a $66 \%$ decrease (figures 6 ). The standard deviation of the mill power was reduced by $145 \mathrm{~kW}$, from $364 \mathrm{~kW}$ to $219 \mathrm{~kW}$. The 2D density plot illustrates how both the load and power plots are more dense and closer to the load high limit as a direct result of the reduction in deviation.

Hulbert (2002) and Craig and Koch (2003) warn that comparing the performance of the improved, post-project circuit to the benchmarked plant can lead to bias. The reason for this bias is due to unmeasured external factors such as ore properties that might be different for the two cases. The recommended way of removing such bias is to reducing the effect of these external factors by conducting an experiment where both the cases are utilised in a structured ON/OFF manner. This could however not be performed due to the expense and time demands of a properly designed $\mathrm{ON} / \mathrm{OFF}$ experiment on an entire circuit. In order to confirm the significant reduction in variability observed in figure 6 , the theoretical minimum variance of the load was investigated to determine whether any change in ore properties are observed. 

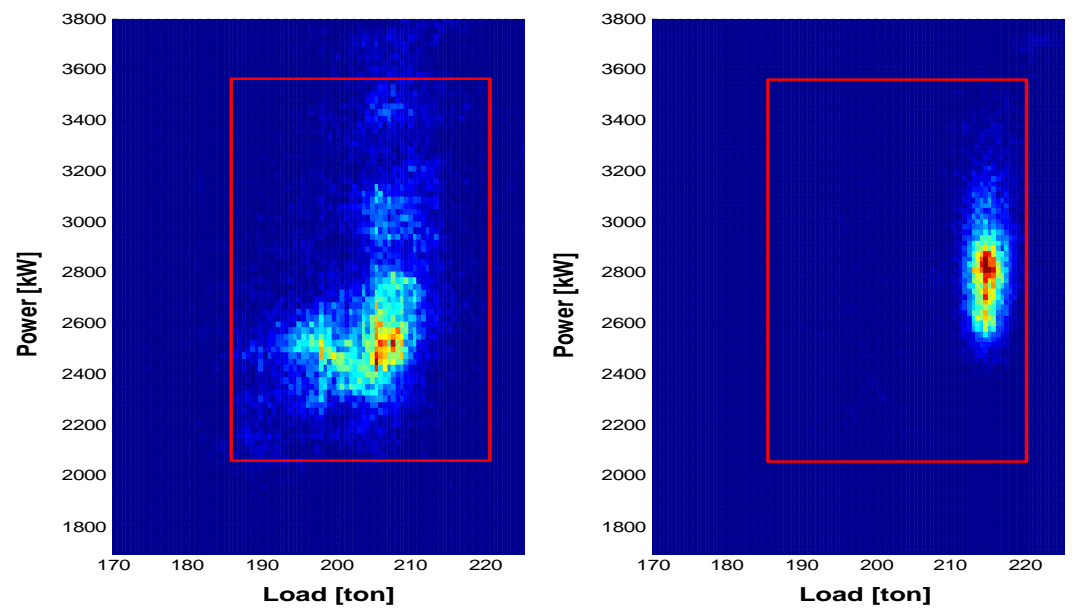

Figure 6: Primary mill power to load curve as a 2D histogram with controller limits (red) a) base-case (1 August to 9 September 2010) and b) first month of MPC operation (19 October to 22 November 2010)

The power spectral density of the mill load indicates a decrease in amplitude during MPC operation at frequencies $\omega<3 \times 10^{-4}$ (figure 7). The mill load appears to converge on the minimum variance approximation at lower frequencies (see figure 7). This concurs with the results shown in figure 6 . The minimum variance of the load indicated very little difference between data for before and after the project. This implies that best-case control performance were similar during the two periods in question and that ore-properties can be considered similar.

To further verify the reduction in variance, the historical standard deviation of load on a month to month basis was compared to that observed as a result of the project. A load standard deviation consistent with the 6.8 ton observed in figure 6 was obtained for the 10 months before the project (figure 8). The reduction in load standard deviation from 6.8 ton to 2.3 ton are observed for three months after commissioning the MPC. This constitutes a $66 \%$ reduction in load variability, which is comparable to the $64 \%$ reduction achieved by Rogers et al. (2010) during a similar MPC application at Lumwana Copper. Further reductions in variability of both MVs and CVs were reported in the lit- 


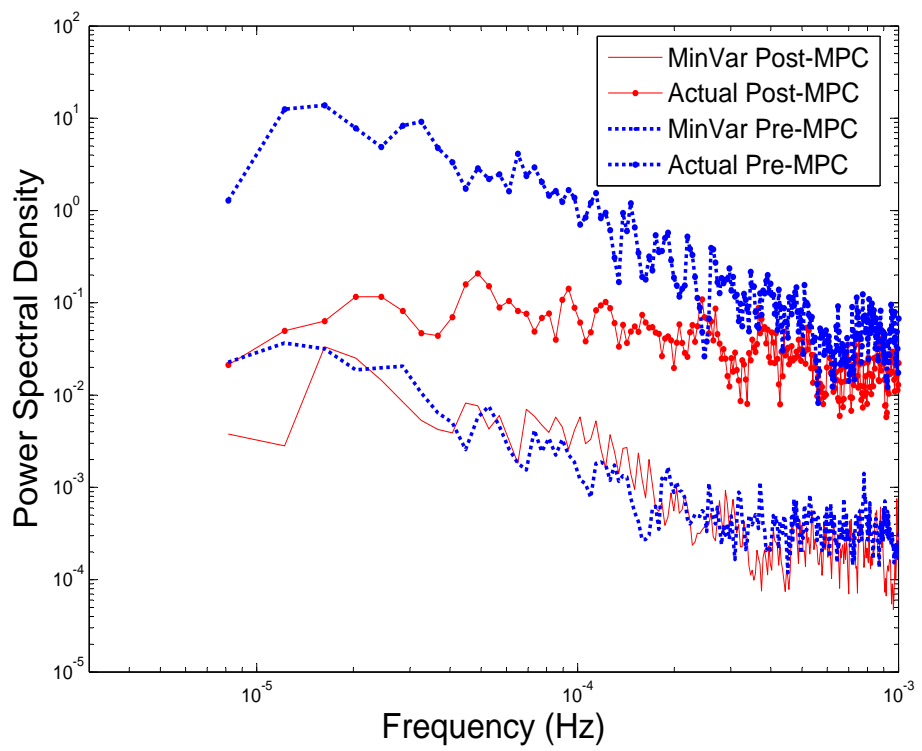

Figure 7: The mill load frequency comparison between pre and post MPC as well as the load's theoretical minimum variance response of the pre and post MPC. The theoretical variance remains similar, while the actual obtained variance is lower than the pre-MPC condition. 
erature when moving from fuzzy-logic expert systems to MPC (Jonas, 2008; Rogers et al., 2010).

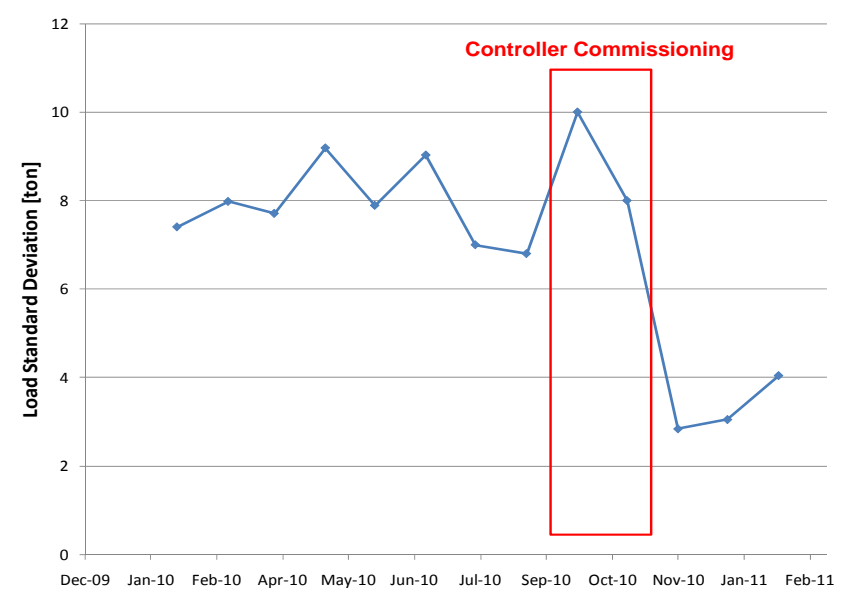

Figure 8: The mill load standard deviation comparison between pre and post MPC over time

Objective Function The effective power utilisation $\eta_{\text {power }}$ was reduced by $11 \%$, from $25.2 \mathrm{kWh} / \mathrm{t}_{-75 \mu m}$ to $22.4 \mathrm{kWh} / \mathrm{t}_{-75 \mu m}$. The zero-hypothesis of no difference between the means was rejected with a $99 \%$ confidence using a two-sample t-test, assuming unequal variance. A time based plot of the normalised shiftly averages shows that this reduction in $\eta_{\text {power }}$ was probably as a result of a change in operating philosophy with a visible change in operating areas for MVs speed and inlet water (figure 9). Note that the measured disturbance feed size remained unchanged which indicates that the change in objective function was probably not due to external factors.

\subsection{Assessment of Neuro-Fuzzy and MPC Performance}

It can be argued that the success of the MPC over the Neuro-Fuzzy controller was due to insufficient tuning or bad design on the part of the latter. There are however fundamental differences between the two algorithms which should lead to more favourable results during MPC operation. The feedforward capability of the MPC allowed for better disturbance rejection with the inclusion of the ore feed size. The MPC uses future prediction to obtain 


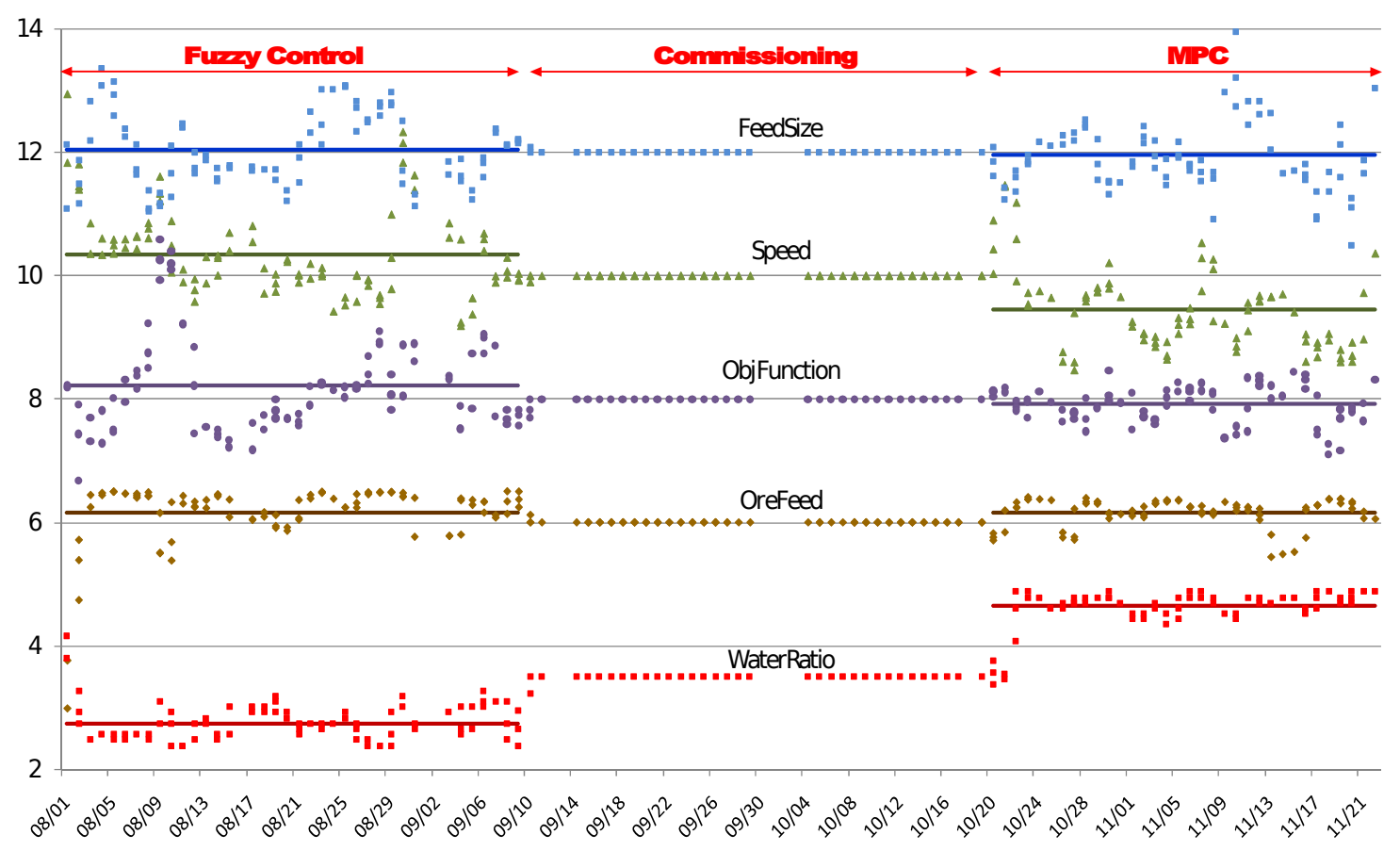

Figure 9: Normalised shiftly averages, time based plot of the objective function, manipulated variables and disturbance variable of the primary mill 
a feasible solution and to avoid possible constraints where the Neuro-Fuzzy relies predominantly on feed-back (Jonas, 2008; Moyano et al., 2010). The minimisation of the effective power utilisation objective is directly included in the MPC algorithm. It is certainly possible to add the above mentioned functionality to the Neuro-Fuzzy controller. However, due the poor scaling of Fuzzy controllers, this will probably result in rule explosion and substantial engineering hours to design and maintain.

\section{Benefit Analysis}

The purpose of this analysis is to determine the financial benefits achieved by stabilising the milling circuit at its optimum. The financial benefit of the milling circuit will be determined using the performance function method devised by Wei and Craig (2009). Note that this benefits analysis reports on potential recovery and hence potential benefit of the project.

\subsection{Performance Functions}

\subsubsection{Profit Function}

The economic consequence in terms of profit is defined by the effect of primary grind on PGM recovery in the flotation circuit (Wei and Craig, 2009; Sosa-Blanco et al., 2000). Due to numerous factors influencing the final PGM recovery of a concentrator, extracting a representative model of the primary mill product size to overall plant performance alone is not a trivial task. The potential recovery to grind relationship for RPMA2 UG2 ore was obtained from laboratory test work. Note that this grind represents the final grind and hence the final plant recovery by assuming perfect flotation operation and a linear recovery-grind relationship within the operating region. The next step is to obtain a model between primary and final grind. A linear model was used which resulted in an RMSE of $1.5 \%$ passing $75 \mu \mathrm{m}$. The RMSE of the model relates to $20 \%$ of the range of the filtered final grind and is therefore considered a poor model. Due to the model quality, the relationship between primary and final grind remains an assumption rather than a proven fact. The effect of primary grind $G(L, I W)$ on potential recovery PR can then be deduced by means of convolution:

$$
P R=0.134 \cdot G\left(L, W_{\text {rat }}\right)+79.61
$$


with model boundaries:

$$
\begin{gathered}
185<L<230 \\
0.13<W_{\text {rat }}<0.26
\end{gathered}
$$

$G\left(L, W_{\text {rat }}\right)$, obtained from the optimisation framework (equation 13). The profit $\mathrm{PF}$ in terms of the main process variables are defined as:

$$
P\left(L, W_{\text {rat }}\right)=\alpha \cdot P R
$$

with $\alpha=\alpha_{1} \cdot F \cdot H G$.

$\alpha_{1}$ is equal to the monetary value of a gram of PGMs in the final concentrate at a certain grade $c_{i}$. F represents the amount of ore treated by the mill in ton per unit time and $\mathrm{HG}$ the head grade in $\mathrm{g} / \mathrm{t}$.

\subsubsection{Cost Function}

As the purpose of this financial benefit model is to provide a metric to compare various optimisation or control strategies, only the operating cost will be included in the cost PF. Fixed costs are considered to be constant. Energy and grinding media are the two highest operating cost factors associated with comminution. As the RPMA2 primary mill is a fully autogenous mill, the economic effect of cost is defined only by the energy consumption of the mill. Note that the cost of liners and the performance of the discharge sump are not included in the scope of this benefit analysis and are considered negligible. The cost function is defined as follows:

$$
C\left(L, W_{\text {rat }}\right)=-\beta \cdot P\left(L, W_{\text {rat }}\right)
$$

Where $\beta$ represents the cost of power in $\$ / \mathrm{kWh}$ and,

$$
P\left(L, W_{\text {rat }}\right)=\frac{\mathrm{d} P}{\mathrm{~d} L} L+\frac{\mathrm{d} P}{\mathrm{~d} W_{\text {rat }}} W_{\text {rat }}
$$

The effect of load on power $\mathrm{P}$ is described by the parabola obtained during trial 1 with $\frac{\mathrm{d} P}{\mathrm{~d} L}=-2.39 L+497.4 \mathrm{~kW} /$ ton (see figure 5 ). The inlet water ratio to power relationship is obtained from the linear step-response model where the steady-state gain represents $\frac{\mathrm{d} P}{\mathrm{~d} W_{\text {rat }}}=43 \mathrm{~kW}$. 


\subsubsection{Overall Performance Function}

The potential nett profit (PNP) given as profit - cost are presented as:

$$
P N P=\alpha \cdot P R\left(L, W_{\text {rat }}\right) f\left(L, W_{\text {rat }}\right)+\beta \cdot P\left(L, W_{\text {rat }}\right) f\left(L, W_{\text {rat }}\right)
$$

The probability density function (PDF) of the grind is defined by the PDF of the load and inlet water ratio which relationship was found to be quadratic (equation 13).

\subsection{Comparing Financial Performance}

One of the main objectives of this project is to determine the financial benefit of stabilising and optimising the primary milling circuit. The PNP function indicates that only load and inlet water ratio are necessary to determine financial impact. Comparing financial performance in terms of minimising PGM losses in the concentrator, $\alpha_{1}$ is considered a function of basket price of refined PGMs, less the operating cost to treat the additional recovered material in the subsequent smelting and refining processes. These costs are confidential. The financial benefit of recovering more PGMs

far outweighs the cost of power, therefore $\alpha \approx 10^{5} \beta$. The highest financial benefit is achieved at the maximum grind and hence potential recovery.

The financial benefit is derived by considering the impact of load and inlet water ratio separately:

\subsubsection{Financial Benefit - Load}

As mentioned, the standard deviation of the load was reduced from 6.8 ton to 2.3 ton with the implementation of the MPC. The financial impact of this project in terms of load is estimated by comparing the following three scenarios at the optimum water ratio $W_{\text {rat }}=0.224$ :

1. The benchmarked plant with load at a mean of 204 ton and standard deviation of 6.8 ton.

2. The benchmarked stability at the optimum load, a mean of 213 ton and at deviation of 6.8 ton.

3. MPC performance at the optimum load, a mean of 213 ton and a deviation of 2.3 ton.

To derive the distribution of the grind, potential recovery and power from the distribution of load, the change of variables for distributions equation is 
used. The distribution of variable $Y=g(X), X$ with probability density function $f_{X}(X)$, is calculated as follows:

$$
f_{Y}(y)=\left|\frac{\mathrm{d}}{\mathrm{d} y}\left(g^{-1}(y)\right)\right| \cdot f_{X}\left(g^{-1}(y)\right)
$$

Where $g^{-1}$ denotes the inverse function

A grind increase of $0.56 \%$ passing $75 \mu \mathrm{m}$ or a potential recovery increase of $0.1 \%$ from $87.2 \%$ to $87.3 \%$ (equation 14 ) was observed by moving the load mean from 204 ton to the optimum 213 ton (comparing scenarios 1 and 2). A further $0.35 \%$ passing $75 \mu \mathrm{m}$ grind or $0.05 \% \mathrm{PR}$ increase was observed when reducing the load variance around the optimum from 6.8 ton to 2.3 ton (comparing scenarios 2 and 3). Figure 10 illustrates how the financial impact manifests by reducing the operating region of the mill and then moving it higher up on the PNP surface.

In order to interpret the benefits analysis plots in figures 10 and 11, it is important to note that due to the high amount of noise in the data, the correlations presented in these plots could not be considered exact. The distributions of the parameters power, potential recovery and grind were thus assumed to be independent. The contours of the various scenarios on all the power to potential recovery plots, represents the $80 \%$ probability of the relative distribution. A one standard deviation distribution of the exact model value is presented as a dotted line in the colour of the respected scenario on the power to recovery contour plot.

\subsubsection{Financial Benefit - Inlet Water Ratio}

Since no significant difference in water ratio variability was observed ( $W_{\text {rat }}$ standard deviation difference of 0.001 is considered negligible), the financial benefits for water will be estimated by investigating two scenarios both at the optimum load of 213 ton:

1. At the benchmarked inlet water ratio mean of 0.178 ,

2. the optimum inlet water ratio, $W_{\text {rat }}=0.224$

Equation 19 is used to derive the distribution for power, grind and potential recovery from the distribution of inlet water ratio. A grind increase of $1.3 \%$ passing $75 \mu \mathrm{m}$ from $34.0 \%$ to $35.3 \%$ was observed by increasing the inlet water to the optimum. This results in a PR increase of $0.17 \%$ from $87.17 \%$ to $87.33 \%$ and an increase on the PNP curve as illustrated in figure 11. 


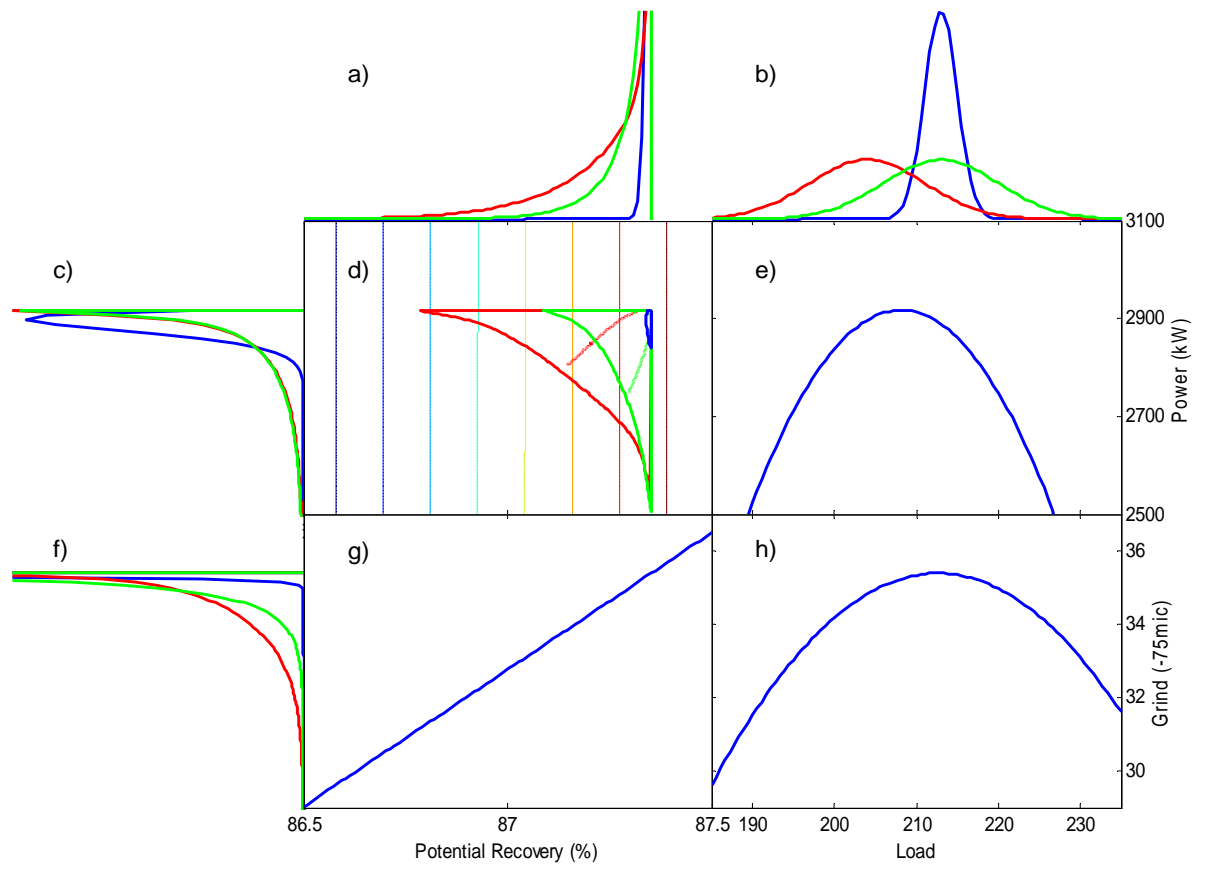

Figure 10: Comparing the potential financial benefit of the benchmarked plant (red), benchmarked controller performance at the optimum load (green) and the performance of the MPC at the load optimum (blue). a) Normal distribution (ND) of potential recovery, b) ND of load, c) ND of power, d) 2D projection of the potential net profit function, e) power to load curve, f) ND of grind, g) grind to potential recovery curve and h) grind to load curve. The contours in d) represent $80 \%$ confidence intervals 


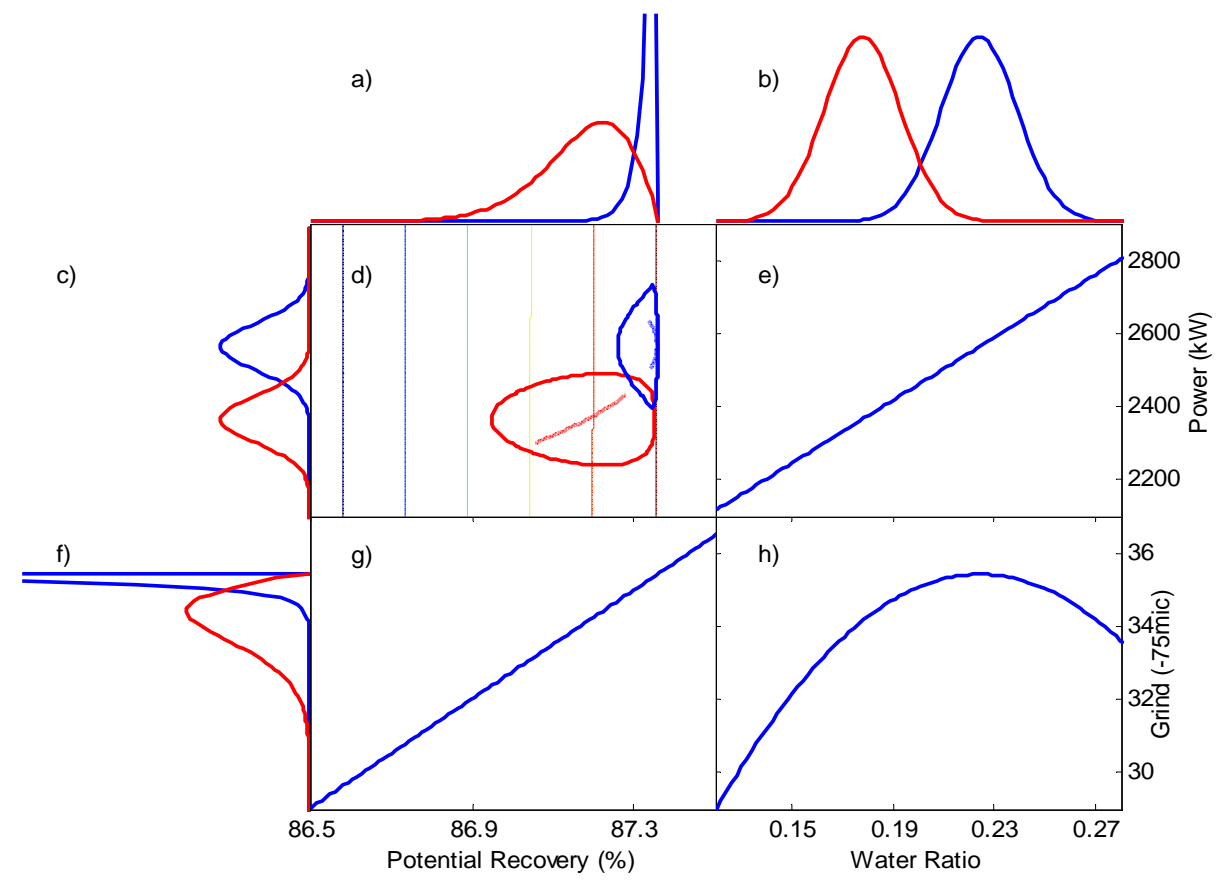

Figure 11: Comparing the potential financial benefit of the benchmarked plant (red) and the inlet water ratio optimum (blue). a) Normal distribution (ND) of potential recovery, b) ND of water ratio, c) ND of power, d) 2D projection of the potential net profit function, e) power to inlet water ratio curve, f) ND of grind, g) grind to potential recovery curve and h) grind to water ratio curve. The contours in d) represent $80 \%$ confidence intervals

The total grind increase observed by moving the load and water ratio mean to 213 ton and 0.224 respectively and stabilising load at a standard deviation of 2.3 ton was calculated at $2.2 \%$ passing $75 \mu \mathrm{m}$. This equates to a potential recovery increase of $0.32 \%$. Recovery increases of smaller than $1 \%$ are very difficult to prove on an industrial site. The benefit calculated from this project remains therefore a theoretical construct, which is subject to various assumptions.

\subsection{Benefit of Variable Speed Milling (VSD)}

The majority of the primary mills in Anglo American Platinum do not have a VSD and hence only have two degrees of freedom for control, they 
are, ore and water feed rate. Since ore feed rate is expected to be at the target throughput, the water is utilised more often to reject any system disturbances. The additional degree of freedom made possible by the mill VSD allows the controller more leverage to reject disturbances while maintaining volumetric fill and viscosity at the respective optimum. The cost of deviating from the optimum during upset conditions can be severe, as was explained in section 4.2. It is therefore important to appreciate that the potential benefit is as a result of the VSD.

\section{Conclusions}

\subsection{Control}

A model predictive controller that utilises the step-response models was implemented and commissioned. The objective function of the controller was designed to optimise effective power utilisation. The controller improved the circuit stability by reducing the standard deviation of the mill load and power by $66 \%$ and $40 \%$ respectively. The controller also reduced its objective function, effective power utilisation by $11 \%$, from $25.2 \mathrm{kWh} / \mathrm{t}$ passing $75 \mu \mathrm{m}$ to $22.4 \mathrm{kWh} / \mathrm{t}$ passing $75 \mu \mathrm{m}$.

\subsection{Benefit Analysis}

The impact of this AG mill optimisation project was to improve the grinding efficiency of the mill, which, resulted in a theoretical increase in overall the PGM recovery of $0.32 \%$. This was achieved by operating the mill at the optimum volumetric fill and viscosity for a given throughput, made possible by the presence of a VSD:

- moving the load from an average of 204 ton to 213 ton (contributed $26 \%$ of total benefit)

- stabilising the load at the optimum grind by reducing the standard deviation from 6.8 ton to 2.3 ton (contributed $16 \%$ of total benefit)

- moving the inlet water ratio average from 0.178 to 0.224 (contributed $58 \%$ of total benefit) 


\section{References}

AspenTech, 2000. AspenTech pty. ltd. DMCplus course notes.

Camacho, E. F., Bordons, C. A., Apr. 2007. Model Predictive Control, 2nd Edition. Springer.

Craig, I., Koch, I., Jan. 2003. Experimental design for the economic performance evaluation of industrial controllers. Control Engineering Practice 11 (1), 57-66.

Hodouin, D., Jms-Jounela, S. L., Carvalho, M. T., Bergh, L., Sep. 2001. State of the art and challenges in mineral processing control. Control Engineering Practice 9 (9), 995-1005.

Hulbert, D., 2002. Evaluation of the economic benefit of milling circuit control. Proceedings of the 15th IFAC Triennial World Congress. Elsevier Science Barcalona, Spain.

Jonas, K., Jan. 2008. Advanded control for mineral processing: Better than expert systems. In: Orford, I. (Ed.), 40th Annual Meeting of the Canadian Mineral Processors. pp. 421-443.

Klimpel, R. R., 1983. Slurry rheology influence on the performance of mineral/coal grinding circuits. part II. Minerals Engineering 35, 21 - 26.

Morell, S., Kojovic, T., 1996. The influence of slurry transport on the power draw of autogenous and semiautogenous mills. Proc SAG '96, Vancouver,, pp 373-389,.

Moyano, G., Viveros, P., Cortes, G., Nov. 2010. Sag and secondary grinding multivariable predictive control coordinated: Division codelco norte. In: Babarovich, V. (Ed.), Automining2010: 2nd International Congress on Automation in the Mining Industry.

Napier-Munn, T., Morell, S., Morrison, R., Kojovic, T., 1999. Mineral Comminution Circuits - Their Operation and Optimization, second edition Edition. Julius Kruttschnitt Mineral Research Centre, The University of Queensland. 
Powell, M., Mainza, A., Dec. 2006. Extended grinding curves are essential to the comparison of milling performance. Minerals Engineering 19 (15), $1487-1494$.

Rogers, M., Almond, D., Maru, T., Becerra, K., Nov. 2010. Model predictive control application at lumwana copper concentrator. In: Babarovich, V. (Ed.), Automining2010: 2nd International Congress on Automation in the Mining Industry.

Skogestad, S., Postlethwaite, I., Oct. 2005. Multivariable Feedback Control: Analysis and Design, 2nd Edition. Wiley-Interscience.

Snyman, J. A., 2005. Practical mathematical optimization: an introduction to basic optimization theory and classical and new gradient-based algorithms. Springer.

Sosa-Blanco, C., Hodouin, D., Bazin, C., Lara-Valenzuela, C., Salazar, J., Sep. 2000. Economic optimisation of a flotation plant through grinding circuit tuning. Minerals Engineering 13 (10-11), 999-1018.

Steyn, C., Brooks, K., de Villiers, P. G. R., Muller, D., Humphries, G., Aug. 2010. A holistic approach to control and optimization of an industrial runof-mine ball milling circuit. In: Gorden, J. (Ed.), IFAC MMM conference 2010. pp. 137-141.

van der Westhuizen, A. P. P., Powell, M. S., 2006. Milling curves as a tool for characterising sag mill performance. In: SAG conference 2006 - Part 2. University of British Columbia, Dept of Mining and Mineral Process Engineering.

Wei, D., Craig, I. K., Feb. 2009. Grinding mill circuits - a survey of control and economic concerns. International Journal of Mineral Processing 90 (14), 56-66. 